The accompanying figure from my paper ${ }^{8}$ shows values at the boundary of the hole. Cauchy strains of order 65 per cent occur at $\theta=90^{\circ}$, while at $\theta=60^{\circ}$ straining-rotation is of order $30^{\circ}$. These are certainly finite values. Other cases of 'plane stress' and 'plane strain' that have been solved are a severely deformed quadrantal cantilever ${ }^{8}$ and $a$ cylinder generated from a flat plate ${ }^{\circ}$. Solutions of the three-dimensional equations are required. Poisson's is the governing equation and indicates complete analogy with the electrical equations. Stress potential is analogous to electric potential, and stress is analogous to gradient of electric force ${ }^{\text {? }}$.

Imperial College of Science and Technology,

K. H. SwaInger

London, S.W.7.

Swainger, K. H., Phil. Mag., 38, 422 (1947)

2 Proc. Seventh Intern. Congr. App. Mech., London, Sept. 1948.

s Communicated to Quart. J. Mech, and App. Math. (June 1950).

- Communicated to Quart. J. Mech. and App. Math. (July 1950).

"Love, A. E. H., "Mathematical Theory of Elasticity", 49 (Cambridge Univ. Press, 1934).

"Weatherburn, C. E., “Advanced Vector Analysis" (G. Bell and Sons, 1937).

'Swainger, K. H., communicated to J. Franklin Inst. (April 1950). App. Sci. Research, Holland (in the press).

'J. App. Mech., 15, 45 (1948).

\section{Anomalous Results of Moth-Proofing Tests}

THE findings reported by Lamb under this title ${ }^{1}$ are unusual but may be explained along the following lines.

When either of the two moth-proofing agents was applied from acid solution at $60^{\circ}$ C., the fabric behaved normally; it had acquired a good proof which gradually diminished in efficiency on repeated washings, because some of the moth-proofing agent was gradually washed out.

When the proofing agent was applied to the fabric along with a dyestuff from a neutral bath at $100^{\circ} \mathrm{C}$., and the bath was acidified only just before the removal of the fabric from it, the quality of the proof was unsatisfactory. The reason is probably that the proofing agents were applied incorrectly; they are often supplied as sodium salts ${ }^{2}$ which have little or no affinity for the wool, and they must be converted into the free sulphonic acids in order to gain substantivity. In the experiment which Lamb describes, this acidification was made only just before the fabric was removed from the bath; the proofing agents, now in the form of free sulphonic acids, would immediately attach themselves to the wool, but irregularly, because before they had time to penetrate the fabric thoroughly, the fabric was removed. Acid dyestuffs behave similarly ; they may be completely applied to the wool in a few minutes, but are irregularly distributed, and dyeing is ordinarily continued for perhaps another half-hour for levelling to take place, for the dyestuff to distribute itself uniformly. Moth-proofing agents of the type described by Lamb are in effect colourless dyestuffs ; they were applied irregularly and had no time to level up. The poor quality of the proof was due to the irregularity of application of the proofing agent.

When the fabric which had the unsatisfactory proof was washed several times with a commercial soap powder, the quality of the proof improved a little. The reason may well be that during washing some opportunity for redistribution over the fabric would be afforded to the proofing agent, still present on the wool as the free sulphonic acid (good commercial soap powders are neutral or nearly so). The more uniform distribution of the moth-proofing agent would improve the quality of the proof ; there would be some loss of proofing agent during washing, but whereas this loss would have a small adverse effect on the quality of the proof, its effect would be more than counterbalanced by the improvement in the proof due to the more uniform distribution of the proofing agent.

3 Church Square,

R. W. MONCRIEFF

Harrogate.

${ }^{1}$ Lamb, K. P., Nature, 166, 37 (1950).

'Moncrieff, R. W., "Mothproofing", 68 (London, 1950).

\section{Ancient Bored Stones}

Wrrh reference to Mr. A. J. H. Goodwin's recent letter under the head of "South African Stone Age Terminology"1, may I point out that the type station of the Magosian is in Uganda, not in Kenya ${ }^{2}$, and in doing so remedy an omission.

I found the Magosi site in 1925 and surveyed and dug it in November 1926, with the aid of funds supplied by the Percy Sladen Trustees. All the many artefacts recovered were sent to Mr. M. C. Burkitt for study and description-or so I thought; but I was away when they were dispatched, and long afterwards I discovered that one specimen, the largest and the only one of its kind, had been omitted from the parcel, and therefore from the description of the culture. It was a rather poor but indubitable example of a bored stone. Unless my memory fails me, it came from the 2-4 ft. level. It was at that time, so far as I know, the oldest on record.

In this connexion it is interesting to note that in December 1949 I was shown, in the National Museum, Bulawayo, a bored stone recently found in association with a Magosian culture in Southern Rhodesia, and was told of another.

Here, perhaps, is the place to recall that nearly twenty years ago I published a short account of a bored stone I had recovered, sixteen months previously, from well-bedded sands and areno-argillaceous beds at a depth of $\mathbf{1 6} \mathrm{ft}$. below a rubble deposit (itself covered by about $4 \mathrm{ft}$. of undisturbed red earth) rich in East African Acheulean implements ${ }^{3}$. This was apparently the $M$-horizon ${ }^{4}$, and the bored stone was in situ. A considerable problem was thus raised.

Three years ago, I seized the chance to re-investigate the matter, and further excavation into the supposed $M$-horizon, near the shaft that had yielded the boredstone, produced not only cleavers, hand axes and other Acheulean-type implements, but also two pieces of flat, artificially ground stone. Clearly the originally supposed $M$-horizon is spurious and re-made, and is bored-stone or post-bored-stone in age.

The significance of the deposits yielding this artefact, and of the pseudo-Acheulean rubble layer above them, will be discussed elsewhere.

Geological Survey,

E. J. WAYLAND Lobatsi,

Bechuanaland Protectorate. July 19.

1 Nature, 165, 1026 (1950),

'Wayland, E. J., and Burkitt, M. C., J. Roy. Anthrop. Inst., 62, 369 (1932)

${ }^{3}$ Nature, 128, 103 (1931) ; and Uganda J., 1, No. 1, 69 (1934).

- Wayland, E. J., Bull. 2, Geol. Surv. Uganda, 69 (1935). 